AFR

78,5

592

Received 12 February 2017 Revised 8 May 2017 16 May 2017 27 June 2017

5 March 2018

7 May 2018

6 June 2018

19 June 2018

Accepted 22 June 2018

\section{Effects of agricultural credit on wheat productivity of small farms in Sindh, Pakistan} Are short-term loans better?

\author{
Abbas Ali Chandio, Yuansheng Jiang, Feng Wei and Xu Guangshun \\ College of Economics, Sichuan Agricultural University, Chengdu, China
}

\begin{abstract}
Purpose - The purpose of this paper is to evaluate the impact of short-term loan (STL) vs long-term loan (LTL) on wheat productivity of small farms in Sindh, Pakistan.

Design/methodology/approach - The econometric estimation is based on cross-sectional data collected in 2016 from 18 villages in three districts, i.e. Shikarpur, Sukkur and Shaheed Benazirabad, Sindh, Pakistan. The sample data set consist of 180 wheat farmers. The collected data were analyzed through different econometric techniques like Cobb-Douglas production function and Instrumental variables (two-stage least squares) approach. Findings - This study reconfirmed that agricultural credit has a positive and highly significant effect on wheat productivity, while the short-term loan has a stronger effect on wheat productivity than the long-term loan. The reasons behind the phenomenon may be the significantly higher usage of agricultural inputs like seeds of improved variety and fertilizers which can be transformed into the wheat yield in the same year. However, the LTL users have significantly higher investments in land preparation, irrigation and plant protection, which may lead to higher wheat production in the coming years.

Research limitations/implications - In the present study, only those wheat farmers were considered who obtained agricultural loans from formal financial institutions like Zarai Taraqiati Bank Limited and Khushhali Bank. However, in the rural areas of Sindh, Pakistan, a considerable proportion of small-scale farmers take credit from informal financial channels. Therefore future researchers should consider the informal credits as well.

Originality/value - This is the first paper to examine the effects of agricultural credit on wheat productivity of small farms in Sindh, Pakistan. This paper will be an important addition to the emerging literature regarding effects of credit studies.
\end{abstract}

Keywords Pakistan, Cobb-Douglas, IV approach, Short-term loan, Wheat productivity

Paper type Research paper

\section{Introduction}

For the modernization of agriculture and rural economic development, agricultural credit plays a vital role. The modernization of agriculture is the process of introducing modern technologies, improving human resources, managing natural resources and environment; however, agricultural credit remains one of the most important factors. Agricultural credit provides an opportunity to farmers for sufficient use of inputs, adoption of modern technologies and more proper allocation of resources to enhance food security and eradicate poverty (World Bank, 2003). Financing of agricultural production, especially through the provision of credit to small-scale farmers, remains the key to macroeconomic development induced by agriculture (Anetor et al., 2016). In Pakistan, the government has implemented a policy to improve farm production and food security by providing agricultural credit to smallholder farmers. The policy was partially successful in increasing the proportion of

\footnotetext{
(C) Abbas Ali Chandio, Yuansheng Jiang, Feng Wei and Xu Guangshun. Published in the AFR Agricultural Finance Review. Published by Emerald Publishing Limited. This article is published under the Creative Commons Attribution (CC BY 4.0) licence. Anyone may reproduce, distribute, translate and create derivative works of this article, subject to full attribution to the original publication and authors. The full terms of this licence may be seen at http://creativecommons.org/licences/by/4.0/legalcode
}

Agricultural Finance Review Vol. 78 No. 5,2018 pp. $592-610$ Emerald Publishing Limited 0002-1466 DOI 10.1108/AFR-02-2017-0010 
households for receiving credit. However, it was less successful to fulfill the demand of farmers (Hussain and Thapa, 2012). This has led to a large gap between the demand for and the supply of credit. Agricultural credit has an essential role in enhancing agricultural production in Pakistan. Researchers showed that agricultural credit positively affected agricultural production yield per acre after controlling the education of farmers and family size (Hussain and Thapa, 2012; Rahman et al., 2014; Saqib et al., 2016; Abdallah, 2016). Previous literature attempted to explain that agricultural credit has a positive and significant impact on agricultural productivity. For example, credit has increased application of fertilizer and pesticides, irrigation and mechanization of agricultural production. Various researchers (e.g. Iqbal et al., 2003; Khandhar and Faruqee, 2003; Rahman et al., 2014; Akudugu, 2016) argue that credit enables farmers to purchase seeds of improved varieties, high efficiency pesticides and fertilizers; therefore, agricultural production increases in a timely and appropriate manner. Few studies, however, have focused on the impact of agricultural credit on wheat productivity in Pakistan. Bashir et al. (2010) examined the impact of credit on wheat productivity by using Cobb-Douglas production function and concluded that the impact of agricultural credit comes through using more wheat seeds per acre, more fertilizers and pesticides per acre, better irrigation and more efficient land preparation. Similarly, Ahmad et al. (2015) observed that agricultural credit has a significant impact on wheat productivity.

Despite the large amount of research on the role of agricultural credit, the researchers treated agricultural credit as a whole. As we know, the loan can be classified into shortterm loan (STL), medium-term loan and long-term loan (LTL) according to the loan period. The STL with a period of one year or less is actually working capital loan mainly used for purchase of agricultural inputs such as seeds of improved varieties, fertilizers and pesticides, while the medium- and LTLs with a period of more than one year are mainly used to invest in fixed assets such as water pumps, tube wells, tractors, and other agricultural related machinery. The policy-makers, bankers and farmers may care about whether or not the STLs have a stronger effect on agricultural productivity than mediumand LTLs. The present study differs from previous researches by attempting to compare the effects of short-term and LTLs on wheat productivity in Sindh Pakistan (to simplify the analysis, the medium- and LTLs are combined and called LTL). Small-scale farmers demand both STL and LTLs. Therefore, it is very interesting and highly policy-related to analyze and compare the effects of STL and LTL on wheat productivity. The remainder of the paper is organized as follows: in sections 2 and 3, we describe the term-wise position of agricultural credit disbursed by Zarai Taraqiati Bank Limited (ZTBL) in Sindh province of Pakistan and province-wise wheat production and area under cultivation in Pakistan. Section 4 reviews related literature on impact of credit on crop productivity. In section 5, we give information on the data and methodology. Next, the estimation results are presented and discussed in section 6 . Finally, the conclusion and policy implications are summarized in section 7 .

\section{Agricultural credits disbursed by ZTBL in Sindh, Pakistan}

In Pakistan, formal agricultural credit is mainly provided to farmers through ZTBL, commercial banks, domestic private banks, cooperatives and Khushhli Bank Limited. These formal sources of credit are working under the supervision of State Bank of Pakistan. The demand of agricultural sector for agricultural credit has been increasing for many years in Pakistan. The ZTBL was established in 1951. ZTBL has a team of 1441 mobile credit officers, 354 branches and 51 regional offices in all over the country. ZTBL is the first bank of Pakistan erstwhile Agricultural Development Bank of Pakistan (ADBP) that provides various loan schemes including Awami Zarai Scheme (farm credit and non-farm credit), Kissan Dost Loan Scheme, Sada Bahar Loan Scheme, One Window Operation Loan Scheme,

\section{Effects of agricultural credit on wheat productivity}


AFR

78,5

594

Asan Qarza Loan Scheme, Shamsi Tawanai Loan Scheme, Rural Development Loan Scheme, and Crop Loan Insurance Scheme for the development of agriculture sector. ZTBL is considered one of the most important formal sources of agricultural credit in Pakistan.

The basic aim of the ZTBL ever since its establishment entails granting loans to farming communities for agricultural development in Pakistan. The total volume of agricultural credit increased from PKR 10,260.5m to PKR 64,897.29m in Pakistan during the period 1996-2010. The same trend was found in the Punjab province of Pakistan where during the same period the total amount of agricultural credit increased from PKR 8,143.54m to PKR 52,995.25m. Similarly, agricultural credit of Sindh province increased steadily from PKR 1,439.31m to PKR 8,093.51m. The province-wise agricultural credit disbursed by ZTBL is depicted in Figure 1 (GOP, 2011).

Furthermore, ZTBL makes short-term, medium-term and LTLs to the farmers. STL is made to the farmers for working capital that is mainly used to purchase improved variety seeds, fertilizers, and pesticide. Medium- and LTLs are provided to farmers for fixed capital that is used to purchase farm implements and improvement of the land tractor, tubewell, farm machinery and land consolidation. The volume of short-term credit increased from PKR 6,122.45m to PKR 57,281.46m, a medium-term loan from PKR 522.26m to PKR 5,265.28m. In contrast, LTL decreased from PKR 3,615.79m to PKR. 2,350.55m from 1995 to 2014. The same pattern was found in Sindh province of Pakistan where during the same period the short-term credit and medium-term credit increased from PKR 1,042.09m to PKR 7,535.50m and PKR 92.82m to PKR 433.96m, respectively. There existed ups and downs in long-term credit in Sindh province of Pakistan where this loan decreased from PKR 304.40m in 1995 to PKR 124.05m in 2014. The term-wise position of agricultural credit disbursed by ZTBL in Sindh province of Pakistan is shown in Figure 2 (GOP, 2011).

Purpose-wise, the loans disbursed to farmers can be classified into eight categories. The loan for fertilizers was the highest annually, followed by seeds since 2001. The amount of total loan increased from PKR 3,159.6m to PKR =27,495.1m from 1995 to 2010. The amount of loans disbursed for fisheries was the lowest, increasing from PKR $7.0 \mathrm{~m}$ to 3.1 million in Pakistan in the period 1995-2010. The amount of loans used for fertilizers increased generally, from PKR 488.5m to PKR 3,617.0m in the period 1995-2010 as depicted in Figure 3 (GOP, 2011).

\section{Province-wise wheat production and area under cultivation in Pakistan}

Wheat is the major cereal crop and it is a staple food of the Pakistani population. It is also a globally traded commodity (Wajid, 2004). In Pakistan almost 80 percent of the farmers grow wheat (Hussain et al., 2012). Figures 4 and 5 show the province-wise wheat production and

Figure 1.

Province-wise agricultural credit disbursed by ZTBL in Pakistan

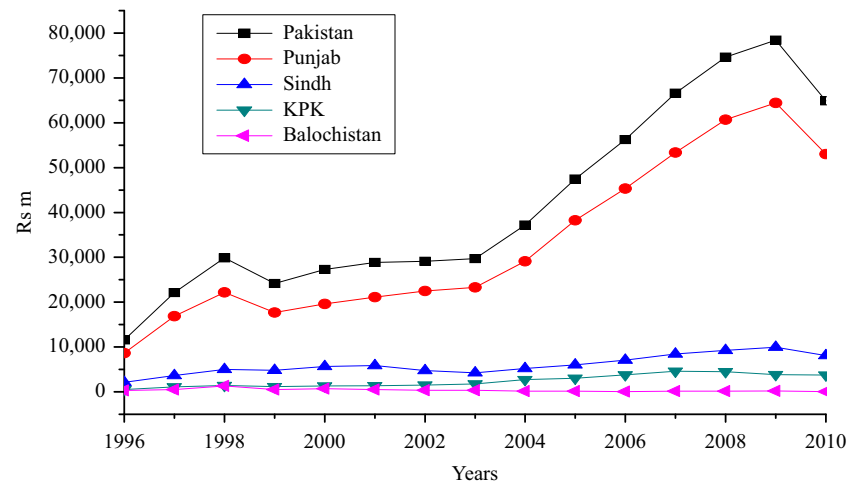

Source: GOP (2011) 


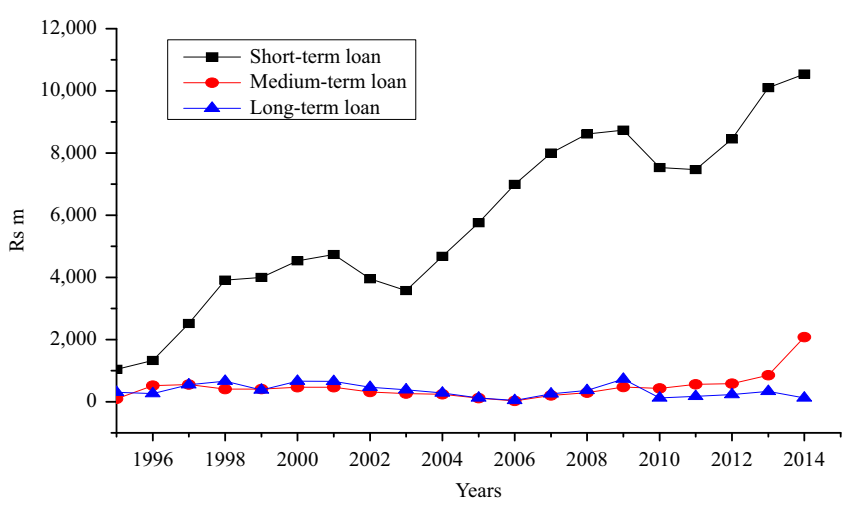

Effects of agricultural credit on wheat productivity

Source: GOP (2011)

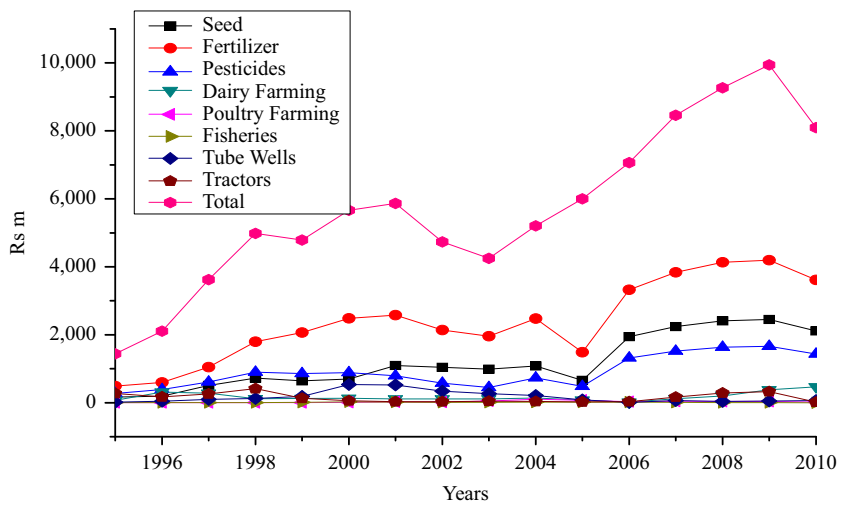

Figure 3.

Figure 2.

Term-wise agricultural credit disbursed by ZTBL in Sindh province of Pakistan

Purpose-wise agricultural credit disbursed by ZTBL in Sindh province of Pakistan

Source: GOP (2011)

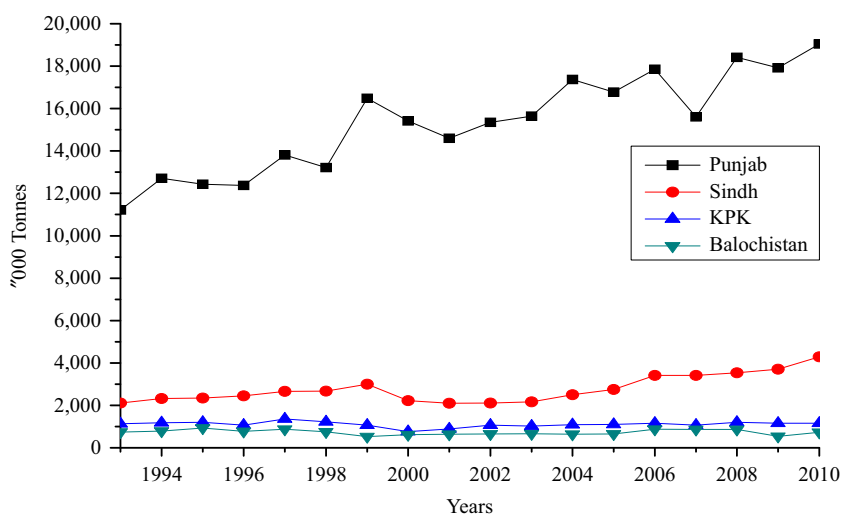

Figure 4. Province-wise wheat production in Pakistan 
AFR
78,5

\section{6}

Figure 5.

Province-wise area under wheat cultivation in Pakistan

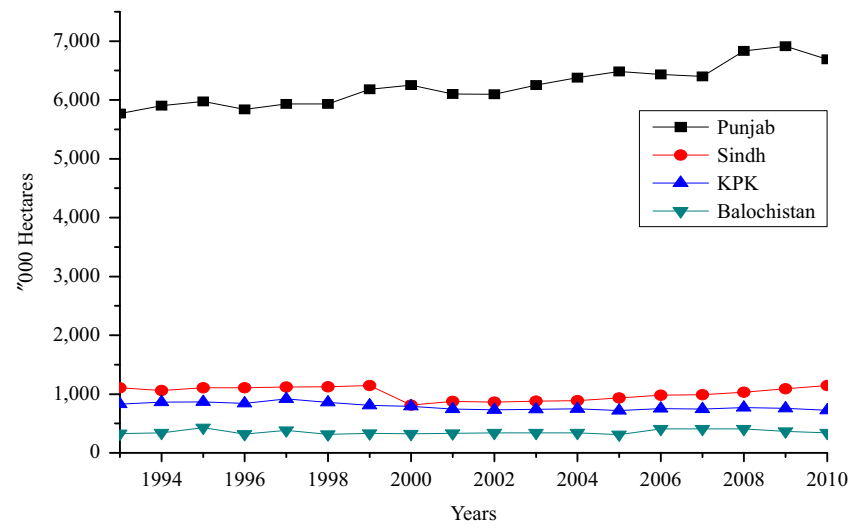

Source: GOP (2011)

land area under cultivation over the period 1993-2011. It is clear that wheat production is higher and cultivated area is larger in Punjab province as compared to those in Sindh, KPK and Balochistan provinces of Pakistan, respectively. Punjab province is the largest wheat producer, while Sindh is the second largest one in wheat production and area under cultivation. Even though Sindh is not the largest producer, it is a good case study for wheat production in Pakistan. Hence, we select Sindh province of Pakistan as the sampling area of the research.

\section{Review of literature}

Credit has a positive impact on agricultural development and generates employment opportunities in rural areas (CBCR, 2004). Agricultural household models not only show that farm credit is required with the limitations of self-financing, but also explain the level of output and the time interval between inputs and outputs (De Janvry and Sadoulet, 1995). World Bank (2006) reported that access of smallholder farmers to formal financial services in rural areas is deficient in spite of the growth in credit distribution worldwide. Boucher et al. (2006) explained that agricultural production constitutes 40 percent of the credit reserved population in Honduras and Peru, with credit reserved production average from 50 percent to 75 percent of the acquired input. Various researchers studied impact of agricultural credit on agricultural productivity in different regions of the world (e.g. Chaudhry and Hussain, 1986; Carter, 1989; Feder et al., 1990; Shrestha, 1992; Zeller et al., 1998; Iqbal et al., 2003; Siddiqi and Baluch, 2009; Khan et al., 2007; Sial et al., 2011; Chandio, Jiang, Joyo and Rehman, 2016; Chandio, Yuansheng, Sahito and Larik, 2016), and found that agricultural credit had a significantly positive impact on agricultural productivity. No doubt, agriculture is the main means for improving the socioeconomic conditions of the farmers. In the context of developing countries, credit is an important tool for increasing farm production (Okurut et al., 2005). The role of credit markets in food production is recognized worldwide. In rural Pakistan, the importance of credit for increasing agricultural production and improving socio-economic conditions of the rural households has been highlighted by previous studies. For instance, Zuberi (1989) found that 70 percent of total formal credit was used for the purchase of primary farm inputs and concluded that increases in agricultural productivity can be explained by changes in the number of farm inputs such as seeds, fertilizers, and pesticides. Likewise, Malik et al. (1991) used a two-stage structure model where the probability of taking formal credit is predicted in the first stage and the predicted value is used in the second stage to 
examine the impact of fertilizer use per acre. Chandio, Jiang, Joyo and Rehman (2016), Chandio, Yuansheng, Sahito and Larik (2016) investigated the impact of institutional credit, cultivated area, fertilizers consumption and water availability on wheat productivity for the 1982 to 2011 period. Using the OLS method, the estimates show that institutional credit, cultivated area and water availability have a positive impact on wheat productivity in Pakistan. Another study of von Braun et al. (1993) shows that smallholders having access to formal credit have 37 percent higher input expenditures than those who do not have access to formal credit. Similarly, other researchers have found negative impact of lack of access to credit on farm production in developing countries such as in Pakistan (Sial and Carter, 1996), India (Kochar, 1997), Kenya and Ethiopia (Freeman et al., 1998), Peru (Guirkinger and Boucher, 2008), Vietnam (Duong and Izumida, 2002) and Tunisia (Foltz, 2004). Thus, agricultural productivity can be boosted through the timely availability of credit which enables farmers to purchase farm inputs like high yield seeds, fertilizers, pesticides and modern farm machinery. Another interesting debate is whether credit to small farms is more productive than credit to large farms. Khandker and Faruqee (2003) observed that agricultural loan disbursed to small-scale farmers is more effective and suitable for farm production than that disbursed to the large-scale farmers. The ADBP gave more facilities and loans to the large-scale farmers than the small-scale farmers, while the loans given to small-scale farmers are proved to be more productive than those given to the large-scale farmers. It also played a very important role in the development of the lifestyle of the small-scale farmers and in reducing their poverty too. Similarly, Iqbal et al. (2003) suggested that the formal sources of credit should be encouraged to expand the agricultural credits for farming sector, especially small-scale farmers. Another study by Fayaz et al. (2006) found that agricultural credit schemes launched by ZTBL had a significantly positive impact on agriculture production and income of the rural households. Nasir (2007) examined that agricultural credit played an important role in agriculture development. It helps smallholders to undertake new investments and adopt new agricultural technologies to enhance agricultural productivity. Lack of access to formal credit has a negative effect on farm production and well-being. Chandio et al. (2017) examined the smallholder farmers' access to agricultural credit in Sindh province of Pakistan. Using the probit model, estimates reveal that a number of socio-economic factors including household size, farming experience, off-income and availability of collateral significantly influenced on smallholder farmers' access to agricultural credit. Chachar (2007) investigated that agricultural credit is the need of both smallholders and large holders for production and development. In Pakistan, almost 95 percent farmers have a landholding size less than 25 acres. In rural areas, the institutional agricultural credits are negligible except that disbursed by ZTBL. Due to complicated procedure of documentation, small-scale farmers lose their interest to apply for agricultural credit from formal sources. Most smallholder farmers prefer to purchase the agricultural inputs at double prices payable after the sales of their products. In the existing literature, there are few works that have been done to compare effects of different terms of agricultural credit on wheat productivity. Therefore, this study attempts to empirically analyze the effects of short term and long term of agricultural credits on wheat productivity of small farms in Sindh, Pakistan.

\section{Data and methodology}

\subsection{Study area}

Sindh is the second highest populated province in Pakistan with a total population of 42.4 million covering a land area of about 140, 914 square kilometers representing the third largest province in Pakistan. Data of this study is derived from a wheat farmer survey in

\section{Effects of agricultural credit on wheat productivity}


AFR

78,5

three districts of Sindh in Pakistan (i.e. Shikarpur, Sukkur and Shaheed Benazirabad). The main food crops cultivated in these districts are wheat, rice, potato, while the main cash crops are sugarcane, cotton, tomato, chilies and onion (GOS, 2010).

\subsection{Data and variables of the study}

In this study, primary data were used. Data were collected from a sample of 180 wheat growers who were selected from three districts of Sindh, Pakistan (i.e. Shikarpur, Sukkur and Shaheed Benazirabad). The random sampling technique was applied for selection of farms. The sample of this study contains only those wheat growers who have acquired credits from ZTBL and Khushhali Bank (KB). Primary data were gathered using a modified version of a structured questionnaire adapted from (Okunade, 2007). The questionnaire covers both open and closed-ended questions. This study used yield of wheat as a dependent variable while per acre costs of major agricultural inputs such as seed, land preparation, fertilizers, plant protection, irrigation and labor and the amount of credit obtained by the wheat growers from ZTBL and $\mathrm{KB}$ used as independent variables. Also, various socio-economic characteristics of the borrowers including age, education level, household size, farming experience and landholding size were used. The analysis was done using both software SPSS version 22 and STATA version 13.

\subsection{Main research method}

Several researchers used different econometric techniques to see impact of credit on crop productivity in different parts of the world. Jacobson and Schedvin (2015) applied logistic and OLS methods to empirically analyze the trade credit and the propagation of corporate failure. The research has been published in world leading journal Econometrica. Bashir (2010) used Cobb-Douglas production function to estimate the impact of credit on rice productivity by treating institutional credit as a whole. Likewise, Ahmad et al. (2015) applied Cobb-Douglas production function to examine the impact of agricultural credit on wheat productivity in district Jhang, Pakistan. Afrin et al. (2017) employed stochastic production frontier approach for assessing the impact of financial inclusion on technical efficiency of paddy farmers in Bangladesh. Likewise, Abdul-HananAbdallah (2016), utilized probit model at the first stage, while stochastic frontier approach at the second stage, to estimate the impact of credit on technical efficiency of Ghanaian maize farmers. The present study is different from the previous studies, in which the researchers treated agricultural credit as a whole to see the impact of credit on wheat productivity, but the present study tried to classify agricultural credits to see the impacts of different term of loans on wheat productivity. Therefore, this study is carried out with three steps. The first step is to estimate the effect of STL on wheat productivity based on a multiple logarithm linear regression (MLLR). The second step is to estimate the impact of LTL on wheat productivity based on a MLLR with the same explanatory variables except the variable of LTL. The last step is to compare the coefficients of STL as well as LTL on wheat productivity in the study area. Following the previous literatures, in this study we used Cobb-Douglas production function to examine the effects of agricultural credits on wheat productivity. Cobb-Douglas production function approach helps to understand the impact of explanatory variables (for instance, costs of farm inputs such as seed, land preparation, fertilizers, pesticides, irrigation, labor and amount of the short-term and the LTLs) on wheat productivity. The model was used by (Bashir et al., 2010; Nadia and Chughtai, 2012; Ahmad et al., 2015; Abdallah, 2016; Afrin et al., 2017). Cobb-Douglas production function can be written as follows:

$$
Y=A X_{1}^{\beta 1} X_{2}^{\beta 2} X_{3}^{\beta 3} X_{4}^{\beta 4} X_{5}^{\beta 5} X_{6}^{\beta 6} X_{7}^{\beta 7}
$$


Taking the natural logarithm of Equation (1) and considering the case of seven explanatory variables, Equation (1) converts to the following form:

$$
\begin{aligned}
L O G Y= & \beta_{0}+\beta_{1} L O G X_{1}+\beta_{2} L O G X_{2}+\beta_{3} L O G X_{3}+\beta_{4} L O G X_{4}+\beta_{5} L O G X_{5} \\
& +\beta_{6} L O G X_{6}+\beta_{7} L O G X_{7}+\mu_{i}
\end{aligned}
$$

This study examines the effects of STL and LTL on wheat productivity and for this regression estimation we used Equation (2). After estimation of the effects of STL and LTL, than now we compare the regression coefficients of STL and LTL by a dummy variable and for this estimation the following equation is used:

$$
\begin{aligned}
L O G Y= & \beta_{0}+\beta_{1} L O G X_{1}+\beta_{2} L O G X_{2}+\beta_{3} L O G X_{3}+\beta_{4} L O G X_{4}+\beta_{5} L O G X_{5} \\
& +\beta_{6} L O G X_{6}+\beta_{7} X_{7}+\mu_{i}
\end{aligned}
$$

In order to deal with the selection bias, this study used the instrumental variable (IV) approach in the analyses estimated with a two-stage least squares (2SLS) method. The 2SLS method has been widely used (Hahn and Hausman, 2002; Murray, 2006) since the approach is suitable to deal with the problems of endogeneity caused by simultaneity, measurement errors or omitted variables among others (Cameron and Pravin, 2009; Greene, 2008; Wooldridge, 2009).

\subsection{Hypothesis of the research}

The following hypotheses have been formulated to examine the effect of the STL in comparison with a medium- and LTL on the wheat productivity of small farms in Sindh, Pakistan:

HO. STL has a no bigger impact on wheat productivity increase than LTL.

H1. STL has a bigger impact on wheat productivity increase than LTL.

\section{Results and discussion}

\subsection{Descriptive analysis}

Table I presents summary statistics of socio-economic characteristics of the surveyed households. The descriptive statistics reveal that the average age of wheat farmers is approximately 41 years. It can, therefore, be stated based on the results that the majority of wheat farmers are in their youthful age and very energetic to carry out the farming-related activities. Farmers, on average, had seven years of formal education, which means that the educational level does not only improve the efficiency of the farmers but also improve their capability to understand and adopt new farming techniques

\begin{tabular}{|c|c|c|c|c|c|}
\hline Variables & Description & Mean & $\mathrm{SD}$ & Min. & Max. \\
\hline Age & Number of years of household head & 41.1778 & 8.881061 & 26 & 69 \\
\hline Education & Years of formal education of the head & 6.80556 & 5.120991 & 0 & 16 \\
\hline Experience & Experience of the sample respondents in years & 28.3722 & 7.214224 & 18 & 50 \\
\hline Household size & Number of persons in the household & 8.96667 & 2.46064 & 5 & 15 \\
\hline Farm size & Number of acres & 13.2148 & 11.55887 & 2 & 62 \\
\hline
\end{tabular}
(Olagunju and Adeyemo, 2007). Generally, it is understood that farmers who had more experience of farming might be more efficient and productive through trial and error (Olagunju and Adeyemo, 2007). The results show that the wheat farmers have on average

Source: Researchers' own calculations, Field Survey (2016)
Effects of agricultural credit on wheat productivity 
AFR

78,5

600

28 years of farming experience. In the study area, the mean household size is nine people. The average landholding in the study area is about 13 acres. The landholding size is an important factor in accessing agricultural credit from formal sources and it is also a symbol of high social status in the society which helps acquire credit from informal financial channels (Hussain and Thapa, 2012; Saqib et al., 2016).

Credit is the basic component of all economic activities like agriculture. Availability and adequate agricultural credit affect crop productivity in the way it facilitates the farmers to purchase improved farm inputs at the sowing time. In Pakistan, formal credit sources provide two main types of agricultural loans which include STL scheme and LTL scheme. The short-term loan scheme is provided for the acquisition of farm inputs including improved seed varieties, fertilizers and pesticides and the maximum duration of this credit scheme is 18 months. The LTL scheme is provided for the purchase of tubewell equipment, machinery and farm implements, reclamation of land, building, and the period of this scheme is 5 to 7 years (Iqbal et al., 2003; Miah et al., 2006). Table II reports that the majority (75.3 percent) of the respondents were STL users while (24.7 percent) of the respondents were LTL users. The results show that the maximum amount of agricultural credit received by the LTL users was PKR 1,000,000.00 with a mean value of PKR 353,104.55 whereas the STL users obtained the maximum amount of agricultural credit was PKR 700,000.00 with on average amount of credit was PKR 253,407.31.

Table III presents summary statistics (minimum, maximum and mean) of the important variables used in the empirical analysis. It reveals that the mean yield per acre of the sampling farms was 38.18 maunds with a minimum of 16.00 maunds and a maximum of 60.00 maunds. The mean per acre seed used was $57.27 \mathrm{kgs}$ while it ranged from $50.00 \mathrm{kgs}$ to $80.00 \mathrm{kgs}$ per acre. Furthermore, the results show that average cost of fertilizers per acre was PKR 9,871.333 with a minimum of PKR 3,700.00 and a maximum of PKR 13,700.00. Similarly, the mean cost of irrigation per acre including canals and tubewell was PKR 1,650.872. Additionally, the average cost of pesticides per acre was PKR 1,008.88.

Table II.

Amount of loan obtained by STL users and LTL users (PKR)

\begin{tabular}{lcccrr}
\hline Loanees & Frequency & Percent & Min. & Max. & Mean \\
\hline STL users & 135 & 75.3 & $20,000.00$ & $700,000.00$ & $253,407.31$ \\
LTL users & 45 & 24.7 & $70,000.00$ & $1,000,000.00$ & $353,104.55$ \\
Total & 180 & 100.0 & $90,000.00$ & $1,700,000.00$ & $606,511.86$
\end{tabular}

Note: SLT, short-term loan users; LTL, long-term loan users

Source: Researchers' own calculations, Field Survey (2016)

\begin{tabular}{llrrr}
\hline Variables & Unit & \multicolumn{1}{c}{ Min. } & \multicolumn{1}{c}{ Max. } & \multicolumn{1}{c}{ Mean } \\
\hline Yield of wheat per acre & Maunds & 16.00 & 60.00 & 38.18 \\
Seed used per acre & Kg & 50.00 & 80.00 & 57.27 \\
Fertilizers cost per acre & PKR & $3,700.00$ & $13,700.00$ & $9,871.33$ \\
Pesticides cost per acre & PKR & 600.00 & $1,800.00$ & $1,008.88$ \\
Irrigation cost per acre & PKR & 200.00 & $5,000.00$ & $1,650.87$ \\
Labor cost per acre & PKR & $1,200.00$ & $5,625.00$ & $3,205.61$ \\
Amount of loan & PKR & $20,000.00$ & $960,000.0$ & $280,639.2$
\end{tabular}

Table III.

Summary statistics of agricultural inputs

Note: 1 maund $=40$ kilograms; $\mathrm{kg}=$ kilogram; $\mathrm{PKR}=$ Pakistani rupees

Source: Researchers' own calculations, Field Survey (2016) 
Finally, the mean amount of agricultural credit was PKR 280,639.2 with a minimum of PKR 20,000 and maximum of PKR 960,000.0

Table IV reports the mean difference of the yield of wheat and key agricultural inputs of STL users and LTL users in the study area. The mean area cultivated by STL users and LTL users are 15.794 and 18.979 acres. The most notable finding of the study is that STL users produced on average 6 maunds per acre more yield of wheat than LTL users, which is statistically significant at 1 percent level. Further findings of the study reveal that the average $2.6 \mathrm{~kg}$ more seed used by STL users compared to LTL users and there is negative significant difference at 10 percent. The cost differences in seed and fertilizers are negative and significant at 1 percent and 5 percent, indicating that STL users had invested more in purchasing improved wheat varieties and chemical fertilizers compared to LTL users to get high wheat productivity and improve income. These results are in line with the findings of Hussain and Thapa (2012), Ahmad et al. (2015) and Saqib et al. (2016). They reported that agricultural credit was used for purchasing of improved farm inputs. On the contrary, cost differences in land preparation, irrigation, and labor are positive and significant at 1 and 10 percent, demonstrating that LTL users had invested more in land preparation, better irrigation and labor as compared to STL users. A preliminary tendency can be found that the STL users have a preference for short-term, quick-acting farm inputs while the LTL users have a preference for longterm, long-acting ones.

\subsection{Empirical analysis}

6.2.1 Effects of short-term loan and long-term loan on wheat productivity with MLLR. First, we have examined the effect of STL on wheat productivity and the results of MLLR are presented in Table V. Cobb-Douglas production function has been used, so the estimated coefficients are actually elasticities of production. The coefficient of STL is $(\log \mathrm{STL}=0.115604)$, which implies that wheat productivity will increase by 0.11 percent if increasing the use of STL by 1 percent. The computed $t$-value for this coefficient is 5.00; this shows that the coefficient is highly statistically significant at 5 percent level. The role of formal agricultural credit in increasing farm production and improving the livelihood of the farmers is recognized worldwide. The maximization of profit is the main aim of every producer. It is evident that short-term credit is an important tool for increasing wheat productivity and improving the living standards of wheat farmers. In rural areas of Sindh, Pakistan, farmers preferred short-term credit to purchase major agricultural inputs including improved variety seeds, fertilizers, pesticides and to invest in land improvement and agricultural machinery. The short-term agricultural loan is normally disbursed by

\begin{tabular}{lccrc}
\hline Variables & Short-term loan users & Long-term loan users & Difference & $t$-value \\
\hline Cultivated area (acre) & 15.794 & 18.979 & 3.184 & 0.635 \\
Wheat yield (maunds) & 40.318 & 34.159 & -6.159 & $-4.108^{* * *}$ \\
Seed rate (kg) & 57.159 & 54.545 & -2.613 & $-1.826^{*}$ \\
Seed cost (PKR) & $2,856.250$ & $2,685.454$ & -170.795 & $-1.985^{* *}$ \\
Land preparation cost (PKR) & $4,132.954$ & $4,565.909$ & 432.954 & $2.693^{* * *}$ \\
Fertilizers cost (PKR) & $10,347.727$ & $9,622.500$ & -725.227 & $-2.466^{* * *}$ \\
Pesticides cost (PKR) & 881.818 & $1,021.590$ & 139.772 & 2.293 \\
Irrigation cost (PKR) & $1,890.909$ & $2,237.886$ & 346.977 & $1.865^{*}$ \\
Labor cost (PKR) & $2,108.181$ & $2,744.045$ & 635.863 & $3.598^{* * *}$
\end{tabular}

Note: *******Significant at 10, 5 and 1 percent levels, respectively

Source: Researchers' own calculations, Field Survey (2016)

Table IV. Difference in yield of wheat and key inputs of STL users and LTL users 


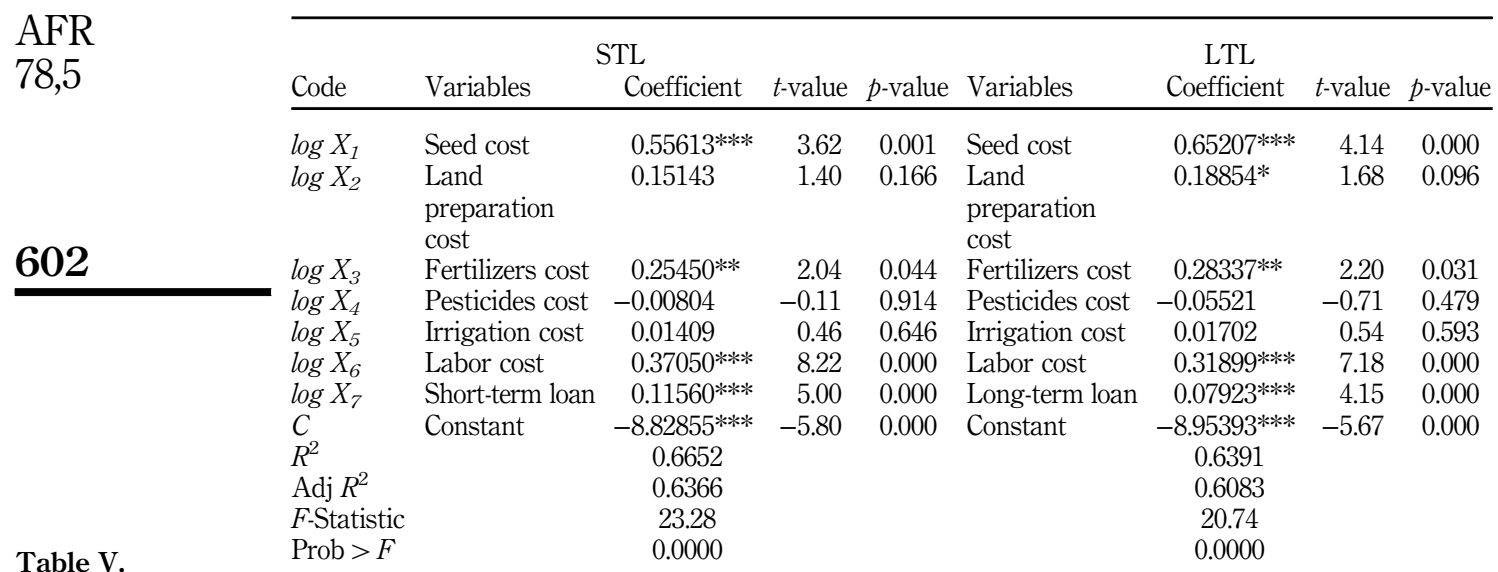

Effects of STL and LTL on wheat productivity
Notes: SLT, short-term loan users; LTL, long-term loan users. *******Significant at 10, 5 and 1 percent levels, respectively

Source: Researchers' own calculations, Field Survey (2016)

formal financial institutions at the start of the sowing season of crops (Khan et al., 2007). Unlike the previous studies (e.g. Javed et al., 2006; Bashir et al., 2010; Nadia and Chughtai, 2012; Ahmad et al., 2015; Chandio, Jiang, Joyo and Rehman, 2016; Chandio, Yuansheng, Sahito and Larik, 2016) that treat the agricultural credit as a whole to estimate the impact of credit on crop productivity, the present study classifies the agricultural credit into the short-term and LTLs and compares their different effects on wheat productivity. After estimating the effect of STL on wheat productivity, again we have examined the effect of LTL. The results are presented in Table V. The coefficient of LTL is $(\log \mathrm{LTL}=0.0792379)$, indicating that per acre wheat productivity increases by 0.07 percent if the use of LTL increases by 1 percent. The calculated t-value for this coefficient is 4.15; this reveals that the coefficient of LTL is statistically significant at 1 percent level. Khan et al. (2007) reported that agricultural credit has played a pivotal role in enhancing agricultural production. Undoubtedly, agriculture is the main means for improving the livelihood of the farmers. In the context of the developing countries, institutional credit is an important tool for agricultural development (Okurut et al., 2005). Wheat is the staple food in Pakistan and it contributes 1.9 percent to the GDP and 9.6 percent of the value added in agriculture (GOP, 2016). Research reveals that credit plays a significant role in increased yield of wheat. For example (Jan et al., 2017; Bashir et al., 2010; Ahmad et al., 2015), concluded that agricultural credit has a significant effect on the yield of wheat. In rural areas of Pakistan, most of the smallholder farmers grow wheat for subsistence only (Asim et al., 2015). In the study area, farmers grow wheat for their home consumption as well as for marketing. Timely and adequate availability of funds enables farmers to cultivate more farmland and benefits more from the economy of scale. The value of the coefficient of multiple determinations i.e. R-square is 0.6652 ; which implies that about 66 percent of the total change in wheat productivity is explained by the seven independent variables. The calculated value of F-Statistic is 23.28 , which is highly significant and presents the overall significance of the model.

When comparing the coefficients of the STL and the LTL, it shows that the STL has a bigger elasticity than the LTL, tentatively implying that the STL has a stronger effect on 
enhancing the wheat yield given the wheat production level in Sindh. This also explains to some extent that much more farmers apply for a STL in the sampling farms in Sindh, Pakistan. Certainly, this tentative result needs confirmation by further test.

6.2.2 Comparative effects of STL and LTL on wheat productivity by a dummy variable. Table VI reports the results for comparison of STL and LTL coefficients estimated using the Cobb-Douglas production function. This study compares the size of dummy variable (STL $=1,0=\mathrm{LTL}$ ) and concludes that the coefficient of STL variable is positive and highly significant than the coefficient of LTL variable. This means that STL has a bigger and stronger effect on wheat productivity in the study area. This finding is to some extent similar to the findings of earlier studies (e.g. Iqbal et al., 2003; Bashir et al., 2010; Abdallah, 2016; Afrin et al., 2017). However, they treated agricultural credit as a whole. According to the term of credit, the agricultural loan can be classified into STL, medium loan, and LTL. Different terms of loan have different effects on crop productivity. STL is considered as a very effective tool in agricultural production since it is frequently used to purchase agricultural inputs such as fertilizers, seeds, pesticides, animal feeds and medicines. Whereas, LTL is supplied for the purchase of farm equipment i.e. tubewell installations, land preparation, tractors/power tiller together with necessary equipment like cultivator, tiller, mouldboard plough, disc harrow, cage wheel, trailer, threshers, combine harvester, cutter binders, spray machinery and drip irrigation, etc. Further, the estimated results show that there is a positive relationship between per acre seed cost and wheat productivity for Cobb-Douglas production function estimation at 1 percent level, which is consistent with earlier studies Coelli and Battese (1996), Jaforullah and Premachandra (2003), Ogundari (2008) and Abdallah (2016). Correspondingly, costs of main inputs such as land preparation, fertilizers and labor positively and significantly affected wheat productivity in Cobb-Douglas production function estimation. These results of the study are similar to the findings of Jaforullah and Premachandra (2003), Ogundari (2008), Bashir et al. (2010) and Buriro et al. (2015). Recently, in developing countries like Pakistan, smallholder farmers' demand for agricultural credit has been increasing. Smallholder farmers need more funds for production and consumption (Khan and Hussain, 2011; Jan and Khan, 2012). Due to a number of constraints like lack of collateral, high interest rates and lack of land ownership smallholder farmers cannot access agricultural credit from formal sources and most of the smallholder farmers rely on informal credit sources (Akudugu, 2012; Ajagbe, 2012; Nouman et al., 2013; Hananu et al., 2015; Fecke et al., 2016; Chandio et al., 2017).

\begin{tabular}{llccrr}
\hline Code & Variables & Coefficient & Robust SE & $t$-value & $p$-value \\
\hline $\log X_{1}$ & Seed cost & $0.5541732^{* * * *}$ & 0.1229697 & \multicolumn{1}{c}{4.51} & 0.000 \\
$\log X_{2}$ & Land preparation cost & $0.2079872^{* * *}$ & 0.0833446 & 2.5 & 0.014 \\
$\log X_{3}$ & Fertilizers cost & 0.4431192 & 0.1066721 & 4.15 & 0.000 \\
$\log X_{4}$ & Pesticides cost & $-0.1275618^{* *}$ & 0.0641132 & -1.99 & 0.048 \\
$\log X_{5}$ & Irrigation cost & 0.0122767 & 0.0215398 & 0.57 & 0.569 \\
$\log X_{6}$ & Labor cost & $0.2814387^{* * *}$ & 0.0507716 & 5.54 & 0.000 \\
$X_{7}$ & DummySTL & $0.1016653^{* * *}$ & 0.0289059 & 3.52 & 0.001 \\
$\mathrm{C}$ & Constant & $-8.031357^{* * *}$ & 1.168912 & -6.87 & 0.000
\end{tabular}

$F$-statistic $=29.43$

Prob $>F=0.000$

$R^{2}=0.605$

Root MSE $=0.18496$

Note: ******Significant at 5 and 1 level, respectively

Source: Researchers' own calculations, Field Survey (2016)

Table VI. Comparison effects of STL and LTL on wheat productivity 
AFR

78,5

604

6.2.3 Results of instrumental variables (2SLS) regression. There may be a reverse causal relationship between credit acquisition and wheat yield. High yield farmers may be observed by the bankers and hence have a higher probability of obtaining credits than low yield farmers. In order to solve the endogenous problem, this study used IV method. The distance from the village to the bank and the availability of transports are selected as IV. IV must satisfy two conditions: In linear models, there are two main requirements for using IV. At the first stage, the IV must be correlated with the endogenous explanatory variables, conditional on the other covariates. If this correlation is strong, then the IV is said to have a strong first stage. At the second stage, the instrument cannot be correlated with the error term in the explanatory equation, conditional on the other covariates. In other words, the instrument cannot suffer from the same problem as the original predicting variable. If this condition is met, then the instrument is said to satisfy the exclusion restriction. First of all, considering high transaction costs due to long distance from banks and high transportation costs farmers are discouraged to apply for credit from formal sources and may turn to the informal sources of credit such as fellow farmers, friends, and relatives. At the same time, the distance from the banks will not affect the farmer's production efficiency. Similarly, various types of transport can provide convenience for farmers to reach the banks. Meanwhile, the types of transportation to the banks don't have an impact on wheat productivity. Based on the above analysis, we used 2SLS method. We used the Stata13 software to perform a 2SLS regression to obtain the regression results. By comparing the estimation results of Cobb-Douglas production function and 2SLS (Tables V and VII), It is evident that after considering the endogeneity problem, the coefficient of the STL in 2SLS becomes larger than in Cobb-Douglas production function regression model. This further suggests that the STL is far more conducive to improving wheat production efficiency than the LTL. The STL has a coefficient of 0.1636604, implying that one percent of increase in the STL will enhance the wheat yield by 0.16 percent.

6.2.4 Constraints to credit access by wheat farmers. During the field survey of this study we asked wheat farmers several questions about problems they faced during the assessment of agricultural credit from formal sources. Results in Table VIII show that 34 percent of wheat farmers were faced with the problem of cumbersome procedure of documentation for the credit. As a rule, the financial institutions provide agricultural credits on the basis of "Pass Book." Whereas the process of acquiring pass book for agricultural credits is very tedious, which usually takes three to four months. Likewise, 47 wheat growers (26.1 percent) reported that they were faced with the problem of delay in

\begin{tabular}{|c|c|c|c|c|}
\hline Code & Variables & Coefficient & $t$-value & $P$-value \\
\hline $\log X_{1}$ & Seed cost & $0.4252736^{* * * *}$ & 2.96 & 0.003 \\
\hline $\log X_{2}$ & Land preparation cost & 0.2977594 *** & 4.06 & 0.000 \\
\hline $\log X_{3}$ & Fertilizers cost & $0.3242725^{* * * *}$ & 3.58 & 0.000 \\
\hline $\log X_{4}$ & Pesticides cost & -0.0608621 & -1.32 & 0.187 \\
\hline $\log X_{5}$ & Irrigation cost & $0.0479007 * * *$ & 2.74 & 0.006 \\
\hline $\log X_{6}$ & Labor cost & $0.4962039 * * *$ & 10.93 & 0.000 \\
\hline $\log X_{7}$ & Short-term loan & $0.1636604 *$ & 1.74 & 0.083 \\
\hline $\mathrm{C}$ & Constant & $-7.434969 * * *$ & -7.86 & 0.000 \\
\hline
\end{tabular}

Table VII.

Regression results of instrumental variables (2SLS)
$R^{2}=0.6456$

Root MSE $=0.17125$

Wald $\chi^{2}=314.01$

Prob $>\chi^{2}=0.0000$

Note: ****Significant at 10 and 1 percent level, respectively

Source: Researchers' own calculations, Field Survey (2016) 
loan disbursement. Due to non-cooperation and lengthy procedure of documentation, smallholder farmers are discouraged to apply for an agricultural loan from financial intuitions. Credit plays a significant role in the farming sector. Therefore, the timely and easy access of agricultural credit is the quickest way to increase wheat productivity. Additionally, 38 respondents (21.1 percent) complained about the high interest rate charged by financial institutions. For instance, ZTBL charged a rate of interest by 14 to 15 percent on production loan as well as on development loan. Whereas KB charged borrowing farmers an interest rate of 20 percent. Similarly, 34 farmers (18.9 percent) complained that they had to bribing the loan officers in order to obtain credits from formal sources. The findings of this study are consistent with the findings of Malik and Nazli (1999), Bashir and Azeem (2008), Akram et al. (2008), Phillip et al. (2009), Tagar and Panhwar (2010), Ugwumba and Omojola (2013), Verteramo Chiu et al. (2014) and Duniya and Adinah (2015).

\section{Conclusion and policy implications}

Maximization of crop productivity is the main aim of every producer. It is a fact that formal agricultural credit has a positive and significant effect on production levels and plays an important role in enhancing crop productivity. This empirical study evaluates the impact of STL and LTL on wheat productivity of small farms in Sindh, Pakistan. In this study primary data was used. Data was collected from a sample of one hundred and eighty wheat farmers who were selected from the three districts of Sindh, Pakistan (i.e. Shikarpur, Sukkur and Shaheed Benazirabad). The random sampling technique was used for selection of the sample. The sample size of this study consists of only those wheat growers who have borrowed STL or LTL from ZTBL and KB. Based on the findings, this study indicates that the majority of loanees are STL users, while the major complaints about the loan disbursement comprise of cumbersome procedures, delay in disbursement and high interest rate. The study reconfirmed that agricultural credit has a positive and highly significant effect on wheat productivity, while STL has a stronger effect on wheat productivity than LTL in the study area. The reasons behind the phenomenon may be the significantly higher usage of agricultural inputs like improved variety seeds and fertilizers which can be transformed into the wheat yield in the same year. However, the LTL user has a significantly higher investment in land preparation, irrigation and plant protection, which may lead to higher wheat production in the coming years. Based on the findings, the current study recommends that formal credit sources including ZTBL, KB, and other Commercial Banks should vigorously develop the STL for boosting up the crop productivity and increase the welfare of rural households. However, for the sustainable increase in wheat yield, there is also a need to accompanying the STL with the LTL and there may be a superimposed effect of the both. Also, formal credit sources should appropriately reduce the interest rate of agricultural credit, and introduce a special interest rate subsidy policy for wheat crop since the profit of wheat production is low, whereas the wheat is the staple food for the people.

\begin{tabular}{lcc}
\hline Nature of Constraints & Frequency & Percentage \\
\hline The cumbersome procedure of documents & 61 & 33.9 \\
Bribery & 34 & 18.9 \\
Delay in loan disbursement & 47 & 26.1 \\
High interest rate & 38 & 21.1 \\
Total & 180 & 100.0
\end{tabular}

Source: Researchers' own calculations, Field Survey (2016)

Table VIII.

Problems stated by the loanees 


\section{Acknowledgements}

The funding was provided by the Soft Science Program of Sichuan Department of Sci-technology: 18RKX0773. The authors would like to thank the College of Economics, Sichuan Agricultural University, Chengdu, China for its financial support of this study. The authors also thank the anonymous reviewers and Prof. Dr CalumTurvey (Chief Editor of Agricultural Finance Review) for insightful comments and suggestions, which led to many improvements contained in this paper. The authors are deeply grateful to the editors and the anonymous reviewers for their helpful comments, which improved the quality of the paper greatly. The authors acknowledge and assume responsibility for any other mistakes or errors within the manuscript.

\section{References}

Abdallah, A.H. (2016), “Agricultural credit and technical efficiency in Ghana: is there a nexus?", Agricultural Finance Review, Vol. 76 No. 2, pp. 309-324.

Afrin, S., Haider, M.Z. and Islam, M.S. (2017), "Impact of financial inclusion on technical efficiency of paddy farmers in Bangladesh", Agricultural Finance Review, Vol. 77 No. 4, pp. 484-505.

Ahmad, A., Jan, I., Ullah, S. and Pervez, S. (2015), "Impact of agricultural credit on wheat productivity in district Jhang, Pakistan”, Sarhad Journal of Agriculture, Vol. 31 No. 1, pp. 65-69.

Ajagbe, F.A. (2012), "Analysis of access to and demand for credit by small scale entrepreneurs; evidence from oyo state, Nigeria”, Journal of Emerging Trends in Economics and Management Sciences, Vol. 3 No. 3, pp. 180-183.

Akram, W., Hussain, Z., Sial, M. and Hussain, I. (2008), "Agricultural credit constraints and borrowing behavior of farmers in rural Punjab”, European Journal of Scientific Research, Vol. 23 No. 2, pp. 294-304.

Akudugu, M.A. (2012), "Estimation of the determinants of credit demand by farmers and supply by rural banks in Ghana's upper east region”, Asian Journal of Agriculture and Rural Development, Vol. 2 No. 2, pp. 189-200.

Akudugu, M.A. (2016), "Agricultural productivity, credit and farm size nexus in Africa: a case study of Ghana”, Agricultural Finance Review, Vol. 76 No. 2, pp. 288-308.

Anetor, F.O., Ogbechie, C., Kelikume, I. and Ikpesu, F. (2016), "Credit supply and agricultural production in nigeria: a vector autoregressive (var) approach", Journal of Economics and Sustainable Development, Vol. 7 No. 2, pp. 131-143.

Asim, M., Hussain, M., Nadeem, N., Ali, A. and Imran, M.A. (2015), "Does credit play a role in increasing the yields of wheat and cotton: a case study of district Sahiwal", Mediterranean Journal of Social Sciences, Vol. 6 No. 4, pp. 482-486.

Bashir, M.K. (2010), "Institutional credit and rice productivity: a case study of District Lahore, Pakistan”, China Agricultural Economic Review, Vol. 2 No. 4, pp. 412-419.

Bashir, M.K. and Azeem, M.M. (2008), "Agricultural credit in Pakistan: constraints and options", Pakistan Journal of Life and Social Sciences, Vol. 6 No. 1, pp. 47-49.

Bashir, M.K., Yasir, M. and Sarfraz, H. (2010), "Impact of agricultural credit on productivity of wheat crop: evidence from Lahore, Punjab, Pakistan”, Pakistan Journal of Agriculture Sciences, Vol. 47 No. 4, pp. 405-409.

Boucher, S., Guirkinger, C. and Trivelli, C. (2006), "Direct elicitation of credit constraints: conceptual and practical issues with an empirical application to Peruvian agriculture", Working Paper No. 07-004, Department of Agricultural and Resource Economics, University of California, Davis, CA.

Buriro, A., Khooharo, A.A. and Ghulam, T. (2015), "Technical efficiency of rice production Sindh, Pakistan: a statistical analysis", Science International, Vol. 27 No. 6, pp. 6225-6230.

Cameron, A.C. and Pravin, K.T. (2009), Microeconometrics Using Stata, Stata Press, College Station, TX. 
Carter, M.R. (1989), "The impact of credit on peasant productivity and differentiation in Nicaragua", Journal of Development Economics, Vol. 31 No. 1, pp. 13-36, doi: 10.1016/0304-3878(89)90029-1.

Chachar, A. (2007), “Agricultural credit: the way forward”, Dawn Group of Newspapers. available at: www.dawn.com/2007/12/03/ebr5.htm

Chandio, A.A., Jiang, Y., Joyo, M.A. and Rehman, A. (2016), "Impact of area under cultivation, water availability, credit disbursement, and fertilizer off-take on wheat production in Pakistan", Journal of Applied Environmental and Biological Sciences, Vol. 6 No. 10, pp. 10-18.

Chandio, A.A., Yuansheng, J., Sahito, J.G.M. and Larik, S.A. (2016), "Impact of formal credit on agricultural output: evidence from Pakistan", African Journal of Business Management, Vol. 10 No. 8, pp. 162-168.

Chandio, A.A., Jiang, Y., Wei, F., Rehman, A. and Liu, D. (2017), "Famers' access to credit: does collateral matter or cash flow matter?-Evidence from Sindh, Pakistan”, Cogent Economics \& Finance, Vol. 5 No. 1, pp. 2-13.

Chaudhry, M.G. and Hussain, Z. (1986), "Mechanization and agricultural development in pakistan [with comments]", The Pakistan Development Review, Vol. 25 No. 4, pp. 431-449.

Coelli, T.J. and Battese, G.E. (1996), "Identification of factors which influence the technical inefficiency of Indian farmers", Australian Journal of Agricultural and Resource Economics, Vol. 40 No. 2, pp. 103-128.

Cygnus Business Consulting Report (2004), "Agricultural credit- biased or unbiased", Bus. Consult. Res. pp. 1-2.

De Janvry, A. and Sadoulet, E. (1995), "Rural poverty and differential rural development programs.

Duniya, K.P. and Adinah, I.I. (2015), "Probit analysis of cotton farmers' accessibility to credit in northern guinea savannah of Nigeria", Asian Journal of Agricultural Extension, Economics \& Sociology, Vol. 4 No. 4, pp. 296-301.

Duong, P. and Izumida, Y. (2002), "Rural development finance in Vietnam: a micro-econometric analysis of household surveys", World Development, Vol. 30 No. 2, pp. 319-335.

Fayaz, M., Jan, D., Jan, A.U. and Hussain, B. (2006), "Effect of short-term credit advanced by ZTBL for enhancement of crop productivity in income of grower", Journal of Agriculture and Biological Sciences, Vol. 1 No. 4, pp. 15-18.

Fecke, W., Feil, J.H. and Musshoff, O. (2016), "Determinants of loan demand in agriculture: empirical evidence from Germany", Agricultural Finance Review, Vol. 76 No. 4, pp. 462-476.

Feder, G., Lau, L., Lin, J. and Luo, X. (1990), "The relationship between credit and productivity in Chinese agriculture: a microeconomic model of disequilibrium", American Journal of Agricultural Economics, Vol. 72 No. 5, pp. 1151-1157.

Foltz, J.D. (2004), "Credit market access and profitability in Tunisian agriculture", Agricultural Economics, Vol. 30 No. 3, pp. 229-240.

Freeman, H.A., Ehui, S.K. and Jabbar, M.A. (1998), "Credit constraints and smallholder dairy production in the East African highlands: application of a switching regression model", Agricultural Economics, Vol. 19 Nos 1/2, pp. 33-44.

GOP (2011), Wheat: Economic Survey of Pakistan, 2010-11, Ministry of Food, Agriculture, and Livestock, Agriculture \& Livestock Division (Economic Wing), Government of Pakistan, Islamabad.

GOP (2016), Economic Survey 2015-16. Finance Division, Economic Advisors, Wing, Islamabad.

GOS (2010), The government of Sindh Pakistan.

Greene, W.H. (2008), Econometric Analysis, 6th ed., Prentice-Hall, Upper Saddle River, NJ.

Guirkinger, C. and Boucher, S.R. (2008), "Credit constraints and productivity in Peruvian agriculture", Agricultural Economics, Vol. 39 No. 3, pp. 295-308. 
Hahn, J. and Hausman, J. (2002), “A new specification test for the validity of instrumental variables”, Econometrica, Vol. 70 No. 1, pp. 163-189.

Hananu, B., Abdul-Hanan, A. and Zakaria, H. (2015), "Factors influencing agricultural credit demand in Northern Ghana”, African Journal of Agricultural Research, Vol. 10 No. 7, pp. 645-652.

Hussain, A. and Thapa, G.B. (2012), "Smallholders' access to agricultural credit in Pakistan", Food Security, Vol. 4 No. 1, pp. 73-85.

Hussain, M., Niaz, M., Iqbal, M., Iftikhar, T. and Ahmad, J. (2012), "Emasculation techniques and detached tiller culture in wheat X maize crosses", Journal of Agricultural Research, Vol. 50 No. 1, pp. 1-19.

Iqbal, M., Ahmad, M. and Abass, K. (2003), "The impact of institutional credit on agricultural production in Pakistan”, Pakistan Development Review, Vol. 42 No. 4, pp. 469-485.

Jacobson, T. and Schedvin, E.V. (2015), "Trade credit and the propagation of corporate failure: an empirical analysis", Econometrica, Vol. 83 No. 4, pp. 1315-1371.

Jaforullah, M. and Premachandra, E. (2003), "Sensitivity of technical efficiency estimates of estimation approaches: an investigation using New Zealand dairy", Economics Discussions Paper No. 0306, Business Department University of Alcalá, Madrid.

Jan, I. and Khan, H. (2012), "Factors responsible for rural household participation in institutional credit programs in Pakistan”, African Journal of Business Management, Vol. 6 No. 3, pp. 1186-1190.

Jan, I., Khan, S., Khan, N.P. and Ashfaq, M. (2017), "Effects of micro-credit programme of Khushali Bank Limited on agricultural productivity in District Mardan, Pakistan”, Sarhad Journal of Agriculture, Vol. 33 No. 4, pp. 688-693.

Javed, M.S., Hassan, S., Adil, S.A. and Ahmad, A.S. (2006), "Impact assessment of micro-credit programme of PRSP on crop productivity", Pakistan Journal of Agricultural Sciences, Vol. 43 Nos 3-4, pp. 209-212.

Khan, N., Jan, I., Rehman, M.U., Mehmood, A. and Akhtar, A. (2007), "The effects of short-term agricultural loans scheme of ZaraiTarraqiati Bank on increase in farm production in district Karak”, Sarhad Journal of Agriculture, Vol. 23 No. 4, pp. 1285-1290.

Khan, R.E.A. and Hussain, T. (2011), "Demand for formal and informal credit in agriculture: a case study of cotton growers in Bahawalpur", Interdisciplinary Journal of Contemporary Research in Business, Vol. 2 No. 10, pp. 308-314.

Khandker, S.R. and Faruqee, R.R. (2003), "The impact of farm credit in Pakistan", Agricultural Economics, Vol. 28 No. 3, pp. 197-213.

Kochar, A. (1997), "Does lack of access to formal credit constrain agricultural production? Evidence from the land tenancy market in rural India", American Journal of Agricultural Economics, Vol. 79 No. 3, pp. $754-763$.

Malik, S.J. and Nazli, H. (1999), "Rural poverty and credit use: evidence from Pakistan", The Pakistan Development Review, pp. 699-716.

Malik, S.J., Mushtaq, M. and Gill, M.A. (1991), "The role of institutional credit in the agricultural development in Pakistan", The Pakistan Development Review, Vol. 30 No. 4, pp. 1039-1048.

Miah, M.K., Alam, A.A. and Rahman, A.H.M.A. (2006), "Impact of agricultural credit on MV Boro Rice cultivation in Bangladesh", Journal of Agriculture \& Rural Development, Vol. 4 No. 1, pp. 161-168.

Murray, M.P. (2006), "Avoiding invalid instruments and coping with weak instruments", Journal of Economic Perspectives, Vol. 20 No. 4, pp. 111-132.

Nadia, A. and Chughtai, M.W. (2012), "Impact of agricultural credit on production of wheat crop: a case study of district Faisalabad-Pakistan", AUDA, Vol. 4 No. 2, pp. 43-51.

Nasir, J. (2007), "Downsize of informal agricultural credit, Business", Daily Dawn, October 17, available at: www.dawn.com/2007/10/17/ebr13.htm

Nouman, M., Siddiqi, M.F., Asim, S.M. and Hussain, Z. (2013), "Impact of socio-economic characteristics of farmers on access to agricultural credit", Sarhad Journal of Agriculture, Vol. 29 No. 3, pp. 469-476. 
Ogundari, K. (2008), "Resource-productivity, allocative efficiency and determinants of technical efficiency of rainfed rice farmers: a guide for food security policy in Nigeria”, Agricultural Economics - ZemedelskaEkonomika, Vol. 54 No. 5, pp. 224-233.

Okunade, E. (2007), "Accessibility of agricultural credit and inputs to women farmers of Isoya Rural Development Project", Research Journal of Agriculture and Biological Services, Vol. 3 No. 3, pp. 138-142.

Okurut, F.N., Schoombee, A. and Berg, S. (2005), "Credit demand and credit rationing in the informal financial sector in Uganda”, South African Journal of Economics, Vol. 73 No. 3, pp. $482-497$.

Olagunju, F.I. and Adeyemo, R. (2007), "Agricultural credit and production efficiency of small scale farmers in south-eastern Nigeria”, Agricultural Journal, Vol. 2 No. 3, pp. 426-433.

Phillip, D., Nkonya, E., Pender, J. and Oni, O.A. (2009), "Constraints to increasing agricultural productivity in Nigeria: a review (No. 6). International Food Policy Research Institute (IFPRI).

Rahman, S., Hussain, A. and Taqi, M. (2014), "Impact of agricultural credit on agricultural productivity in Pakistan: an empirical analysis", International Journal of Advanced Research in Management and Social Sciences, Vol. 3 No. 4, pp. 125-139.

Saqib, S., Ahmad, M.M., Panezai, S., Hidayatullah and Khattak, K.K. (2016), "Access to credit and its adequacy to farmers in Khyber Pakhtunkhwa: the case of Mardan district", Sarhad Journal of Agriculture, Vol. 32 No. 3, pp. 1-8.

Shrestha, C.M. (1992), "Institutional credit as a catalyst for agricultural sector growth: evidence from Nepal", Journal of Economic Development, Vol. 17 No. 2, pp. 137-144.

Sial, M. and Carter, M. (1996), "Financial market efficiency in an Agrarian economy: microeconometric analysis of the Pakistani Punjab", Journal of Development Studies, Vol. 32 No. 5, pp. 771-798.

Sial, M.H., Awan, M.S. and Waqas, M. (2011), "Role of institutional credit on agricultural production: a time series analysis of Pakistan", International Journal of Economics and Finance, Vol. 3 No. 2, pp. 126-132.

Siddiqi, M.W. and Baluch, K.N. (2009), "Institutional credit: a policy tool for enhancement of agricultural income of Pakistan”, International Research Journal of Arts \& Humanities (IRJAH), Vol. 37, pp. 158-174.

Tagar, H.K. and Panhwar, I.A. (2010), "Agricultural credit in Sindh: issues and recommendations", Australian Journal of Basic and Applied Sciences, Vol. 4 No. 8, pp. 4099-4106.

Ugwumba, C.O.A. and Omojola, J.T. (2013), "Credit access and productivity growth among subsistence food crop farmers in Ikole local government area of Ekiti State, Nigeria", Journal of Agricultural and Biological Science, Vol. 8 No. 4, pp. 351-356.

Verteramo Chiu, J., Khantachavana, L.V.S. and Turvey, G.C. (2014), "Risk rationing and the demand for agricultural credit: a comparative investigation of Mexico and China", Agricultural Finance Review, Vol. 74 No. 2, pp. 248-270.

Von Braun, J., Malik, S.J. and Zeller, M. (1993), Credit Markets, Input Support Policies and the Poor; Insight from Africa and Asia, International Food Policy Research Institute, Washington, DC.

Wajid, S.A. (2004), "Modeling development, growth and yield of wheat under different sowing dates, plant populations and irrigation levels", $\mathrm{PhD}$ thesis, Department of Agron, University of Agriculture, Faisalabad.

Wooldridge, J.M. (2009), Introductory Econometrics: A Modern Approach, 4th ed., South-Western/ Cengage Learning, Mason, $\mathrm{OH}$.

World Bank (2003), “The world development report”, The World Bank, Washington. DC, available at: www-wds.worldbank.org/external/default/WDSContentServer/WDSP/IB/2006/09/06/000112 742_20060906121359/Rendered/ PDF/267630REACHING0THE0RURAL0POOR0.pdf (accessed October 5, 2015).

World Bank (2006), “Access to financial services in Nepal”, available at: http://siteresources.worldbank.org/ NEPALEXTN/Resources/publications/4158301174327112210/complete.pdf (accessed June 8, 2011). 
AFR

78,5

610
Zeller, M., Diagne, A. and Mataya, C. (1998), "Market access by smallholder farmers in Malawi: implications for technology adoption, agricultural productivity and crop income", Agricultural Economics, Vol. 19 Nos 1-2, pp. 219-229.

Zuberi, H.A. (1989), "Production function, institutional credit and agricultural development in Pakistan”, The Pakistan Development Review, Vol. 28 No. 1, pp. 43-56.

\section{Further reading}

Asogwa, B.C., Ihemeje, J.C. and Ezihe, J.A.C. (2011), "Technical and allocative efficiency analysis of Nigerian rural farmers: implication for poverty reduction”, Agricultural Journal, Vol. 6 No. 5 , pp. 243-251.

Chandio, A.A., Yuansheng, J. and Koondher, M.A. (2015), "Raising maize productivity through agricultural credit a: case study of commercial banks in Pakistan", European Journal of Business and Management, Vol. 7 No. 32, pp. 159-165.

\section{Corresponding author}

Yuansheng Jiang can be contacted at: yjiang@sicau.edu.cn 